\title{
CAEP 2015 Academic Symposium: Current State and Recommendations to Achieve Adequate and Sustainable Funding for Emergency Medicine Academic Units
}

Eddy S. Lang, MD*; Jennifer D. Artz, $\mathrm{PhD}^{\dagger}$; Ryan D. Wilkie, $\mathrm{BSc}^{\ddagger}$; lan G. Stiell, MD, MSc ${ }^{\S \uparrow ;}$ Claude Topping, MD"; François P. Belanger, MD**; Marc Afilalo, MD ${ }^{\dagger+}$; Tia Renouf, MD ${ }^{\ddagger \neq}$; Anthony Crocco, $\mathrm{MD}^{\S \S}$; Kelly Wyatt, $\mathrm{BA}^{\dagger}$; Jim Christenson, $\mathrm{MD}^{\text {ITा }}$

\section{ABSTRACT}

Objectives: To describe the current state of academic emergency medicine (EM) funding in Canada and develop recommendations to grow and establish sustainable funding. Methods: A panel of eight leaders from different EM academic units was assembled. Using mixed methods (including a literature review, sharing of professional experiences, a survey of current EM academic heads, and data previously collected from an environmental scan), 10 recommendations were drafted and presented at an academic symposium. Attendee feedback was incorporated, and the second set of draft recommendations was further distributed to the Canadian Association Emergency Physicians (CAEP) Academic Section for additional comments before being finalized.

Results: Recommendations were developed around the funding challenges identified and solutions developed by academic EM university-based units across Canada. A strategic plan was seen as integral to achieving strong funding of an EM unit, especially when it aligned with departmental and institutional priorities. A business plan, although occasionally overlooked, was deemed an important component for planning and sustaining the academic mission. A number of recommendations surrounding philanthropy consisted of creating partnerships with existing foundations and engaging multiple stakeholders and communities. Synergy between academic and clinical EM departments was also viewed as an opportunity to ensure integration of common missions. Education and networking for current and future leaders were also viewed as invaluable to ensure that opportunities are optimized through strong leadership development and shared experiences to further the EM academic missions across the country.
Conclusions: These recommendations were designed to improve the financial circumstances for many Canadian EM units. There is a considerable wealth of resources that can contribute to financial stability for an academic unit, and an annual networking meeting and continuing education on these issues will facilitate more rapid implementation of these recommendations.

\section{RÉSUMÉ}

Objectifs: L'étude visait à décrire l'état actuel du financement des unités d'enseignement de la médecine d'urgence (MU) au Canada et à élaborer des recommandations sur I'accroissement et la durabilité du financement.

Méthode: Un groupe composé de huit chefs de file provenant de différentes unités d'enseignement de la $M U$ a été formé. S'appuyant sur diverses méthodes de recherche (examen de la documentation, mise en commun d'expériences professionnelles, enquête menée parmi les directeurs actuels d'unité d'enseignement de la MU et étude de données provenant d'une analyse environnementale antérieure), le groupe a formulé 10 recommandations préliminaires qui ont été présentées au cours du symposium sur les affaires universitaires. Après avoir tenu compte des observations faites par les participants, le groupe a modifié en conséquence les recommandations préliminaires, qu'il a ensuite transmises à la section des affaires universitaires de l'Association canadienne des médecins d'urgence (ACMU) afin de recueillir d'autres observations avant d'en arriver à la rédaction définitive.

Résultats: L'exercice a donné lieu à la formulation de recommandations concernant les problèmes de financement

From the *Department of Emergency Medicine, University of Calgary, Calgary, AB; †Canadian Association of Emergency Physicians (CAEP), Ottawa, ON; $¥$ Faculty of Medicine, University of Calgary, Calgary, AB; §Department of Emergency Medicine, University of Ottawa, Ottawa, ON; IOttawa Hospital Research Institute, University of Ottawa, Ottawa, ON; IFaculté de médicine, Université de Laval, Québec City, QC; **Department of Pediatrics, Faculty of Medicine, University of Calgary, Calgary, AB; ††Faculty of Medicine, McGill University, Montréal, QC; $¥ \neq D i s c i p l i n e$ of Emergency Medicine, Memorial University of Newfoundland, St. John's, NL; §§Department of Pediatrics, Division of Emergency Medicine, McMaster University, Hamilton, ON; and IITDepartment of Emergency Medicine, University of British Columbia, Vancouver, BC.

Correspondence to: Dr. Eddy Lang, Academic and Clinical Department Head for Emergency Medicine, Cumming School of Medicine Alberta Health Services, University of Calgary, 3330 Hospital Drive NW, Calgary, Alberta T2N 4N1; Email: Eddy.Lang@albertahealthservices.ca 
qui avaient été cernés, et des unités d'enseignement de la MU rattachées à des universités de partout au Canada ont proposé des solutions. Le plan stratégique était perçu comme un élément faisant partie intégrante du bon financement des unités d'enseignement de la $\mathrm{MU}$, tout particulièrement lorsque celui-ci est aligné sur les priorités des départements et des établissements. Par ailleurs, le plan d'activités, parfois négligé, était considéré comme un outil important de la planification et de la durabilité de la mission d'enseignement. Un certain nombre de recommandations ayant trait à la philanthropie consistait en l'établissement de partenariats avec des fondations existantes et en l'engagement d'un grand nombre d'intervenants et de communautés. La synergie entre les départements d'enseignement théorique et d'enseignement clinique de la MU était aussi perçue comme un facteur propice à l'intégration de leurs missions communes. Enfin, la formation et le réseautage aux yeux des chefs de file actuels et futurs étaient aussi considérés comme des éléments cruciaux d'optimisation des possibilités par l'établissement d'un pouvoir d'influence bien assis et par la mise en commun d'expériences afin de faire progresser encore davantage la mission de l'enseignement de la MU partout au pays.

Conclusions: L'élaboration de ces recommandations visait à améliorer la situation financière de nombreuses unités d'enseignement de la MU au Canada. Les ressources susceptibles de contribuer à la stabilité financière des unités d'enseignement ne manquent pas, et la tenue d'une réunion annuelle de réseautage ainsi que la formation continue sur les problèmes décrits faciliteront la mise en œuvre rapide de ces recommandations.

Keywords: emergency medicine, funding

\section{INTRODUCTION}

It is difficult to define an amount of funding that is appropriate for all academic units. It could be argued that all emergency medicine (EM) academic departments/divisions/sections (collectively referred to as "units") require more resources to offer ideal training and research environments. Counterarguments focus on the overall economy, societal priorities, and underfunding of all academia in general. EM is one of the newest academic disciplines and still struggles for full recognition of its contributions to the health care system and for equitable support within faculties of medicine. The observation of the academic funding disparities across Canada ${ }^{1}$ argues for discussion, justification, and the provision of increased funding for EM in many, if not all medical schools. The level of funding must be aligned with the mission and goals of the medical school and the regional health authority, with the ultimate objective being the enhancement of emergency care delivery and patient outcomes.

Academic funding provides the support for the three key missions of any discipline in a medical school: undergraduate education, postgraduate education, and research. Although it is atypical to use the term "unit" for the EM academic department, this is being used pragmatically to reflect that not all medical schools have a formal departmental or divisional structure for EM. ${ }^{1}$ The effective delivery of an academic mission requires that an EM academic unit have administrative support, infrastructure, and focused medical leadership, all of which require funding for individual staff and faculty positions. Recognition of the contributions that EM academic units provide to the training of emergency physicians, as well as to all other future physicians, is relevant to educational programs.

Herein, the current state of EM academic funding in Canada is summarized, and recommendations for its improvement are provided. The objectives of this panel were to: 1) report on funding for academic EM units across Canada; 2) compare academic unit support with expectations in the areas of administration, undergraduate education, postgraduate education, and research; and 3) recommend strategies to grow and establish sustainable funding across Canadian university EM units.

\section{METHODOLOGY}

\section{Funding panel, data collection, and recommendations}

A panel of eight leaders from EM was assembled and included representatives from across Canada. Five formal teleconferences were held over nine months leading up to the CAEP 2015 Academic Symposium ${ }^{2-8}$ on Leadership. This panel reviewed the literature, drew from professional experience, conducted a survey of current EM academic heads, and reviewed the data from an environmental scan. Discussions culminated in five themes that facilitated the formulation of 10 recommendations, which were presented at the Academic Leadership Symposium on May 30, 2015, in Edmonton, Alberta. The 80 attendees, which included EM leaders, researchers, educators, administrators, attending clinicians, residents, and medical students, 


\begin{tabular}{|c|c|c|}
\hline Search Number & Search & Result \\
\hline 1 & $\begin{array}{l}\text { (emergency physician* or emergency department* or emergency medicine).mp. [mp = title, original title, name of } \\
\text { substance word, subject word heading, keyword heading word, protocol, supplementary concept word, rare } \\
\text { disease supplementary concept word, unique identifier] }\end{array}$ & 68,936 \\
\hline 2 & limit 1 to (English language and full text) & 16,416 \\
\hline 3 & $\begin{array}{l}\text { (funding or payment models or payment mechanisms or fee models or financial incentives or remuneration or fee } \\
\text { for service or economic models or salaries).mp. [mp = title, original title, name of substance word, subject word } \\
\text { heading, keyword heading word, protocol, supplementary concept word, rare disease supplementary concept } \\
\text { word, unique identifier] }\end{array}$ & 58,480 \\
\hline 4 & limit 3 to (English language and full text) & 13,116 \\
\hline 5 & 1 and 2 and 3 and 4 & 146 \\
\hline
\end{tabular}

provided feedback as the recommendations were presented. The feedback was subsequently incorporated into revised recommendations that were distributed to the CAEP Academic Section electronically for final comment.

For the literature review, the search strategy combined predefined MeSH headings (Table 1) and searched MEDLINE and Embase using Ovid from 1946 to April 28, 2015 (with limitations set to English language and full text). An independent review by two authors agreed that none of the 146 identified articles were directly relevant to the topic of interest. Canadian Institute for Health Information (CIHI), Statistics Canada, and the Canadian Health Service Research Foundation (now called the Canadian Foundation for Health Improvement [CFHI]) websites were searched for academic funding information, but no such information was available.

Academic heads were surveyed about the qualitative issues related to current funding in academic units. This information complemented a broad environmental scan that addressed administration, education, research, and funding. For the qualitative issues, a 40-question survey specific to academic funding was developed, pilot tested, and refined by expert feedback. It asked about current unit funding sources, support for didactic and bedside teaching, support for research and administrative requirements, remuneration, philanthropic resources, funding challenges, and advice for funding the academic mission (Appendix 1). Recognizing the sensitivity of financial information, it was specified that none of the responses would be attributed to an individual or program. The electronic survey was hosted on FluidSurveys (Fluidware Corporation, Ottawa, ON). Each of the 17 heads of EM academic units was contacted electronically by a panel member to encourage participation. Data were collected over a one-month period from mid-April 2015 to mid-May 2015. Comments were collated for themes. Data were analyzed in Microsoft Excel 2013 (Microsoft Corp., Redmond, WA), and descriptive statistics were reported.

The environmental scan of Canadian EM units had been previously conducted and was an 84-question survey. The panel was allowed access to the blinded and collated data. The survey had been completed by electronically sending it to the heads (or equivalent) of each academic EM unit at the 17 Canadian medical schools. A follow-up call by the survey administrators ensured that questions were answered uniformly. The responses were recorded into a Microsoft Excel 2013 spreadsheet for analysis. The investigator (IS) validated the site data with each head (or equivalent) with a follow-up phone call to review each response. Descriptive statistics including proportions, means, medians, and ranges were calculated.

\section{Overall academic unit leadership and administrative support}

The majority of the academic heads (16/17) responded to the survey. The funding for the academic mission's leadership and administrative support comes from both internal and many external sources. Of the 16 respondents, all but one indicated that they had universityderived funds (Table 2). Eleven academic units cited research grants as a source of funds. The Ministry of Health (or Education Ministry), hospitals, physician groups, and alternative funding plans (AFPs) funded six of respondent academic units. Other sources of funding included: province-specific sources, philanthropic donations, and offshore resident fees.

Over half of respondents (9/16) reported that physicians on a fee for service or a mixed model contributed 
a portion of their clinical earnings in order to support the academic mission of their EM unit. This was accomplished through mandatory percentage of earnings (e.g., $15 \%, 5 \%, 2 \%, \$ 5$ per hour, or $\$ 2$ per hour), or through identified funds that are matched by the Ministry of Health.

Philanthropic sources appeared to be underused and were inconsistently sought to support the academic mission in half of respondents' units. The eight EM units that reported on philanthropic support identified their primary donor groups (including physicians, industry, hospital grants, endowments, patients, and pharmaceutical education grants), where the average gift ranged from $\$ 500$ (commonly from physicians) to $\$ 100,000$ (from private donors and endowment funds). Reasons for not using philanthropic resources included the effort required, difficulty in attracting EM donations, and failure to consider the option.

Upon the review of this manuscript, attention was brought to the roles of free open access medical education (FOAMed), social media, and novel teaching methods in the academic mission. The growth in these media is undeniable, and their effects on education and research are documented. ${ }^{9-12}$ These freely available tools may be leveraged to reduce the costs of knowledge sharing and may potentially be a beneficial marketing tool to prospective philanthropic donors on the value of emergency medicine.

\begin{tabular}{l}
$\begin{array}{l}\text { Table 2. Sources of current funding to support the academic } \\
\text { mission for Canadian EM units. }\end{array}$ \\
\hline Funding Source
\end{tabular}

\section{Education funding}

Respondents reported that bedside on-shift teaching of medical students and residents was financially supported in 10 and 12 of their centers, respectively. Didactic teaching to residents or medical students was also financially supported in 14/16 of respondents' units. The respondents described how financial support for didactic and bedside teaching was rewarded and included a pointsbased compensation system, honorarium (stipend), hourly fee, shift allowance, and previous contract stipulation. Over a third (6/16) considered the degree of financial support that remunerates educators (for teaching) in Canadian EM units to be inadequate.

Suggestions for the most appropriate funding for undergraduate and postgraduate education leadership and infrastructure support differed between respondents and indicated that appropriate funding depended on class size, number of rotations, number of electives, and other expectations (i.e., simulation or undergraduate medical education research). Respondent recommendations for how to appropriately support research faculty included grants, awards, medical school contributions, hospital foundation support, research institutes, and AFPs. Specific staffing recommendations varied by quantity and type of position (e.g., research director, research administrative support, and funded research faculty positions). Strategies suggested to obtain support for academic funding included negotiating with universities, government policy, arguing to better meet accreditation standards, and quantifying unit funding needs in alignment with specific and especially increasing demands. Opinions were evenly split on whether there was adequate support for program directors, clerkship leads, and simulation coordinators (Table 3).

\section{Research funding}

Many (13/16) reported that research had internal funding sources, which included grants, awards, practice plans,

\begin{tabular}{|lcccc|}
\hline \multicolumn{4}{|l|}{ Table 3. Opinions on whether clinician educators with leadership roles receive adequate financial support. } \\
\hline $\begin{array}{l}\text { Clinician educators with } \\
\text { leadership roles }\end{array}$ & $\begin{array}{c}\text { Adequate financial } \\
\text { support } n(\%)\end{array}$ & $\begin{array}{c}\text { Do not have adequate financial } \\
\text { support } n(\%)\end{array}$ & $\begin{array}{c}\text { Not applicable } \\
n(\%)\end{array}$ & $\%$ \\
\hline Program directors $(n=16)$ & $9(56)$ & $7(44)$ & 0 & 94 \\
Clerkship leads $(n=15)$ & $6(60)$ & $6(40)$ & 0 & 38 \\
Simulation coordinators $(n=16)$ & $4(25)$ & $11(69)$ & $1(6)$ & 25 \\
\hline
\end{tabular}


volunteered group clinical earnings, AFPs, university support, or unit-based research, education, and innovation funds.

A majority of respondents (13/16) considered the degree of financial support for research activities in their units to be inadequate. Similarly, 13/16 considered it important to have researchers that are university funded (without any external salary support). Suggestions to achieve improved salary support for researchers included having successful researchers (and research units), providing awards for researchers, and emphasizing that a unit of EM may have an unproportioned allocation (i.e., that start-up funds are often required to support a new and emerging research program). Alternatively, recommendations to achieve appropriate funding for EM research programs outside of salary support included developing endowments, philanthropy, matched funding, improved AFPs, and partnering with industry, which was similar to a very recently published Canadian academic research funding analysis. ${ }^{8}$

\section{CHALLENGES TO ACADEMIC FUNDING}

The funding survey explored opinions on the main challenges faced in obtaining appropriate funding for the academic mission. As a surrogate, "appropriate" was defined as an adequate level of financial support for the expected activities related to education, research, and other extra-clinical endeavors necessary to realize the vision and goals of the EM academic unit. Four main challenges emerged in maintaining the academic budget: 1) budget constraints with inflating costs and growing programs; 2) AFPs having low clinical/ academic split or shrinking in size; 3) physicians not being a part of an AFP; and 4) lack of support from the government or Faculty of Medicine. To address these concerns, recommendations were formulated under themes focused on approaches to tackle these barriers to achieving optimal funding. The five themes included planning, philanthropic support, alignment of academic and clinical activities with academic mission, development of a leadership network, and leadership development.

\section{RECOMMENDATIONS}

\section{Funding theme 1: Planning}

Recommendation 1: Academic units should develop a strategic plan, including a vision, a mission, and goals, ideally aligning with university, hospital, and ministerial mandates.

Recommendation 2: Strategic plans should address both the clinical and academic missions and be interwoven in a way that optimizes synergy and mutual benefit.

Recommendation 3: Academic units should develop a business plan (as part of the strategic plan) that clarifies: 1) the financial resources needed to achieve the mission and goals; 2) the sources of income; and 3) effective spending of the resources.

Although seemingly a fundamental step in any academic EM unit, the panel felt that the development of a strategic plan was an extremely important but often overlooked step. The strategic plan must balance the needs of undergraduate education, postgraduate education, and research (and innovation). There is not a single roadmap that will accommodate all EM units. Consideration of the local funding environment is the first step in developing a strategic plan. Finding the balance between a mission that will excite, engage, and focus the unit, yet leave the door open for new opportunities, is challenging, and therefore the plan should be revisited on a regular basis.

Strategic plans should consider both the clinical and academic units for mutual benefit. Strategic plans are at risk if they are not seen as adding direct value to patients and the health delivery system. The development of most or all extra-clinical portfolios and activities should be relevant to the clinical and operational challenges of the clinical emergency departments and the broader emergency health delivery systems. Depending on the local environment, faculty members may have combined or separately-defined roles, as primarily clinical (usually associated with teaching responsibilities) or funded academics. A willingness from the faculty to actively support the strategic initiatives is necessary, since all are critical to the overall success of the academic unit.

A well-defined business plan clarifies the financial picture across the academic unit and is fundamental to the success of the academic mission. This potentially challenging exercise may often be based on incomplete data and best estimates, but it should demonstrate a necessary attention to specifics to ensure that any funder or potential funder can fully understand the reality and the gaps. Engaging a professional with a business background is essential to developing a business plan (and its budget) that will meet the scrutiny of stakeholders. 
Funding theme 2: Philanthropic support

Recommendation 4: Philanthropic support for the academic mission of the EM unit should be pursued primarily through the current hospital and/or university fund development programs.

Recommendation 5: Clinician involvement in philanthropy, as spokespersons or liaisons with potential individual or group donors, should be encouraged and incentivized in both clinical and academic affairs as a prerequisite to effective partnering with fund development offices in hospitals and at the university.

Recommendation 6: Partners, including graduating residents, grateful patients, or wealthy givers, should be engaged (or invited) to share their vision for EM through direct feedback, project funding choices, leadership opportunities, and volunteering.

Philanthropy is often a part of the funding for the academic units in other disciplines, but EM is rarely engaged in garnering philanthropic support for both the clinical and non-clinical mission of the academic unit. Without this tradition of working with donors and institutional foundations, EM is often marginalized when it comes to philanthropy. Fund development offices in both university and hospital settings are likely to see this as untapped potential. Once they understand the many heart-touching stories that emanate from all emergency departments, there will be a willingness to support fundraising efforts for EM activities. Strengthening community engagement and the relationships with potential donors is hard work but can bring great rewards.

The involvement of clinicians in academics will facilitate effective partnering with philanthropic partners. Clinical emergency departments with a successful track record in obtaining philanthropic support have noted that fund development offices are more inclined to support the academic mission when their colleagues are visible and highly engaged in hospital and university activities. The larger the footprint of the emergency units on committees and other activities, the more likely that key stakeholders will draw on EM wisdom in planning fundraising activities, and hence support EM-specific initiatives. Specifically, fund development offices who see EM faculty as engaged and supported are more likely to foster meetings and interactions with donors who may be inclined to support EM-related projects.

Identifying partners with overlapping visions can expand fundraising opportunities. The pool of individuals who have benefited from EM academia and clinical care is large and often overlooked. Providing these potential donors with visible opportunities to learn about a unit's academic activity through high-quality media, and providing them with the opportunity to make earmarked donations, can be invaluable. Branding a unit's philanthropic resource can be linked to campaigns, fundraising activities, or everyday materials encountered in the emergency departments - for example, scrubs - to stimulate interest in potential donors.

\section{Funding theme 3: Alignment of clinical activities and academic mission}

Recommendation 7: Academic EM units should develop guiding financial policies that address: 1) the clinical group expectations for donated clinical earnings to the academic mission; 2) the expectations of the relative value of academic time to clinical remuneration.

Recommendation 8: When clinical income is sought to support the academic mission, academic activities should be aligned to the clinical department, considering continuing medical education, faculty development, and research.

Policies around the support of the academic units by donated clinical earnings and the expectations of academic times must be established. While often contentious and dictated by existing agreements with health ministries, universities, and institutions, most emergency physicians would agree that there are tangible benefits to working in an academic setting. These include resident support during clinical work and high-quality educational opportunities, to name a few. While not a universal phenomenon, most Canadian academic units draw on clinical earnings to some degree, to support the academic mission of the units. Coming to a consensus on this strategy and agreeing on how clinical earnings will support academics (i.e., salary support or project support) should be determined prior to development of a comprehensive business plan.

In order for clinical earnings to support the academic mission, it must be clear how these activities achieve both direct and indirect value to the members of the unit, including those who have a largely clinical focus to their practice. Funding these academic efforts may be essential to launch careers, to provide all unit members with academic opportunities, to develop skills 
(e.g., bedside teaching), and to learn more about global health initiatives. Communicating the gamut of extraclinical activities that the academic program supports, making opportunities for involvement by faculty through workshops, and showcasing events, like a research day, are essential to demonstrating this value.

\section{Funding theme 4: Academic EM leadership networking}

Recommendation 9: Canadian academic unit heads should meet on an annual basis to share, network, and grow.

There is a real opportunity for growth of EM, if the Canadian EM academic leaders met annually to share challenges and solutions. The Academy of Academic Chairs of EM is a network of department chairs, largely US-based, that participate in an email list-serv and meet annually at a two- to three-day retreat to share wisdom on a wide range of leadership topics. Vice-chairs or likely successors are also encouraged to attend as part of their leadership development activities. The funding panel views this type of forum as highly beneficial, despite the US health care focus.

\section{Funding theme 5: Leadership development}

Recommendation 10: The CAEP annual meeting should offer a leadership track covering key fundingrelated topics for both academic and hospital leaders that could include negotiation (with the university, hospital, and ministry), philanthropy, practice plans, entrepreneurship, etc. Topic selection should be tied to a needs assessment drawn from engaged leaders and leaders in development.

The CAEP annual conference is an ideal opportunity for the formal education of EM leaders on funding in domains of negotiation, philanthropy, and other opportunities. Leadership development, an area that has been addressed by the Canadian Medical Association (CMA), may be lacking in specific EM-oriented requirements. While leadership development in health care is likely to be similar among multiple disciplines, the nature of EM in society and health care institutions (including hospitals) poses unique challenges and opportunities. With this in mind, and potentially in conjunction with CMA support, an annual leadership track at the CAEP meeting was strongly endorsed.

\section{NEXT STEPS}

Support for the academic EM missions across Canada are varied and largely dictated through the local environments. There are tremendous opportunities in sharing and learning from these varied approaches. This panel strongly feels that the development of a long-term plan, leveraging the available resources, and partnerships will improve the financial circumstances for many Canadian EM units. In this exercise, it was also discovered that there is a wealth of untapped knowledge from colleagues, and that annual meetings and continuing education on these issues will be important for the future success of academic EM. The Leadership Working Group of the CAEP Academic Section is already in discussions with the CAEP 2016 Conference Organizers and Conference Chairs for the inclusion of a Leadership Track. A consultation service to engage single academic units in more in specific discussions with successful academic leaders is now established through CAEP. Leaders at each academic unit may find useful ideas in the three Leadership reports with recommendations (Leadership, Governance and Administration and Funding ${ }^{13,14}$ ). Finally, the working group will continue to discuss how it can best facilitate the recommendations and perhaps bring new information and insights at an update at its next Academic Leadership Symposium, to be held in 2018.

Acknowledgements: The authors acknowledge the support of Angela Marcantonio, Cathy Clement, and Rachel Baril in the administration and data collection of the environmental scan.

Competing Interests: None.

\section{SUPPLEMENTARY MATERIAL}

To view supplementary material for this article, please visit http://dx.doi.org/10.1017/cem.2016.16

\section{REFERENCES}

1. Stiell IG. Personal Communication - Academic EM Environmental Scan; 2015.

2. Sherbino J, Van Melle E, Bandiera G, et al. Education scholarship in emergency medicine part 1: innovating and improving teaching and learning. CfEM 2014;16(Suppl 1): S1-5.

3. Bandiera G, Leblanc C, Regehr G, et al. Education scholarship in emergency medicine part 2: supporting and developing scholars. CFEM 2014;16(Suppl 1):S6-12. 
4. Bhanji F, Cheng A, Frank JR, et al. Education scholarship in emergency medicine part 3: a "how-to" guide. CFEM 2014;16(Suppl 1):S13-8.

5. Stiell IG, Artz JD, Perry J, et al. Executive summary of the CAEP 2014 Academic Symposium: How to make research succeed in your department. CFEM 2015;17(3):328-33.

6. Calder LA, Abu-Laban RB, Artz JD, et al. CAEP 2014 Academic Symposium: "How to make research succeed in your department: Promoting excellence in Canadian emergency medicine resident research". CFEM 2015;17(5):591-9.

7. Perry JJ, Snider CE, Artz JD, et al. CAEP 2014 Academic Symposium: "How to make research succeed in your emergency department: How to develop and train career researchers in emergency medicine". CFEM 2015;17(3):334-43.

8. Vaillancourt C, Rowe BH, Artz JD, et al. CAEP 2014 Academic symposium: "How to make research succeed in your department: How to fund your research program". CFEM 2015;17(4):453-61.

9. Purdy E, Thoma B, Bednarczyk J, et al. The use of free online educational resources by Canadian emergency medicine residents and program directors. CFEM 2015; 17(2):101-6.

10. Hayes BD, Kobner S, Trueger NS, et al. Social media in the emergency medicine residency curriculum: social media responses to the residents' perspective article. Ann Emerg Med 2015;65(5):573-83.

11. Sherbino J, Frank JR. @SirBill: the power of social media to transform medical education. Postgrad Med $f$ 2014;90 (1068):545-6.

12. Thoma B, Joshi N, Trueger NS, et al. Five strategies to effectively use online resources in emergency medicine. Ann Emerg Med 2014;64(4):392-5.

13. Sinclair D, Worthington JR, Joubert G, et al. CAEP 2015 Academic Symposium: Leadership within the EM Academic Community and Beyond. CFEM 2016; doi:10.1017/cem.2016.9.

14. Petrie D, Chopra A, Chochinov A, et al. CAEP 2015 Academic Symposium: Recommendations for University Governance and Administration for Emergency Medicine. CFEM 2016; doi:10.1017/cem.2016.22. 